\title{
O gênero Chloris (Poaceae) em Pernambuco, Brasil
}

\author{
The genus Chloris (Poaceae) in Pernambuco, Brazil
}

\author{
Jefferson Rodrigues Maciel ${ }^{1,4}$, Wegliane Campelo da Silva ${ }^{2} \&$ Maria Bernadete Costa-e-Silva $^{3}$
}

\begin{abstract}
Resumo
Com o objetivo de colaborar com o conhecimento da riqueza de Poaceae em Pernambuco, foi estudado o gênero Chloris Sw. As coletas foram realizadas no estado, bem como dados foram coligidos de levantamento em herbários da região. Foram registradas sete espécies de Chloris em Pernambuco: C. barbata Sw., C. elata Desv., C. exilis Renv., C. gayana Kunth, C. orthonoton Döll, C. pycnothrix Trin. e C. virgata Sw. O gênero apresenta distribuição ampla em todas as zonas fitogeográficas do estado. Chloris gayana, C. barbata e $C$. pycnothrix estão citadas na literatura como potenciais forrageiras.
\end{abstract}

Palavras-chave: Caatinga, Chloridoideae, florística, Nordeste, gramíneas, taxonomia.

\begin{abstract}
Aiming to contribute to a better knowledge of the richness of grasses occurring in Pernambuco, a study of the genus Chloris $\mathrm{Sw}$ in the state was performed. Field work was conduced in that state and herbarium surveys were made. Seven species of the genus Chloris were recorded: C. barbata Sw., C. elata Desv., C. exilis Renv., C. gayana Kunth, C. orthonoton Döll, C. pycnothrix Trin. and C. virgata Sw. The genus present a wide distribution in all phytogeographical zones in Pernambuco. Chloris gayana, C. barbata and C. pycnothrix have been recorded in the literature as potential forage plants.
\end{abstract}

Key words: Caatinga, Chloridoideae, floristic survey, Northeastern Brazil, grasses, taxonomy.

\section{Introdução}

A família Poaceae é composta por cerca de 10.000 espécies agrupadas em aproximadamente 700 gêneros, amplamente distribuídas por todo o planeta, constituindo elementos dominantes em uma grande variedade de ambientes (GPWG 2001).

$\mathrm{O}$ gênero Chloris $\mathrm{Sw}$. pertence à tribo Cynodonteae, subfamília Chloridoideae e destaca-se por várias de suas espécies serem utilizadas como forrageiras. As 55 espécies conhecidas se encontram distribuídas nos trópicos e regiões temperadas de ambos os hemisférios (Clayton \& Renvoize 1986) e se caracterizam por apresentar de 1-4 antécios estéreis, sendo o antécio inferior aristado, glumas similares, páleas menores que os lemas e lodículas geralmente soldadas na base (Molina 1996).

Estudos clássicos ampliaram o conceito de Chloris incluindo espécies atualmente reconhecidas para Eustachys Desv. (Anderson 1974; Pereira \&
Barreto 1985). No entanto, Molina \& Rúgolode-Agrasar (2004) seguem a tendência de manter esses gêneros separados (Renvoize 1984; Molina 1996; Longhi-Wagner 2001), posição também adotada neste estudo e que está de acordo com as evidências filogenéticas mais modernas (Peterson et al. 2010), as quais sugerem que Chloris é monofilético ou poderia ser ampliado para englobar algumas espécies de Tetrapogon Desf. e Lintonia Stapf.

Dada a importância ecológica e econômica das espécies de Chloris, o conhecimento da diversidade regional deste gênero é imprescindível para fundamentar planos de usos dos pastos nativos no Brasil. Diante disto, o presente estudo tem como objetivo realizar um tratamento taxonômico de Chloris em Pernambuco e fornecer dados sobre a distribuição e aspectos ecológicos do gênero na região.

\footnotetext{
${ }^{1}$ Jardim Botânico do Recife, BR 232 km 7,5, Curado, 50000-230, Recife, PE, Brasil.

${ }^{2}$ Universidade Federal do Amapá, Rod. Juscelino Kubitschek km 02, Jardim Marco Zero, 68902-280, Macapá, AP, Brasil.

${ }^{3}$ Instituto Agronômico de Pernambuco, Av. Gal. San Martin 1371, Bonji, 50761-000, Recife, PE, Brasil.

${ }^{4}$ Autor para correspondência: jeff.r.maciel@gmail.com
} 


\section{Material e Métodos}

Para este trabalho foram realizadas coletas de exemplares férteis em diversas regiões fitogeográficas de Pernambuco entre os anos de 2002 e 2011. Dados também foram obtidos no banco de dados do Catalogue of New World Grasses-CNWG (Soreng et al. 2000) e nas coleções depositadas nos herbários ASE, CEN, CPATSA, HST, HUEFS, IBGE, IPA, JPB, PEUFR, RB, SP, SPF, UB e UFP (acrônimos conforme Thiers 2012, exceto CPATSA, Herbário da Embrapa Semi-Árido, e HST, Herbário Sérgio Tavares da Universidade Federal Rural de Pernambuco).

A descrição das espécies foi baseada na análise morfológica das estruturas sob estereomicroscópio. A terminologia morfológica seguiu Longhi-Wagner (2001) e a correção nomenclatural seguiu Soreng et al. (2000) e Filgueiras (2012). Para a identificação e estudo de cada táxon foram empregados exemplares previamente identificados por especialistas e a literatura específica do gênero (Anderson 1974; Longhi-Wagner 2001; Molina \& Rúgolo-de-Agrasar 2004). O material selecionado indicado no texto segue o critério de um exemplar por zona fitogeográfica, de acordo com a classificação de Andrade-Lima (1960) e todo o material examinado para este trabalho está relacionado na Lista de exsicatas. As informações sobre o potencial forrageiro foram obtidas em Nascimento \& Renvoize (2001) e Smith et al. (1982).

No trabalho de campo as populações foram georreferenciadas e seus habitats avaliados e descritos. As informações de distribuição geográfica foram complementadas com os dados provenientes das etiquetas das coleções de herbário. Amostras de herbários sem coordenadas geográficas nas etiquetas foram georreferenciadas com coordenadas dos topônimos conhecidos ou, na ausência destes, com as coordenadas dos municípios.

Esses dados foram visualizados com o software DIVA-GIS (Hijmans et al. 2001). Os mapas base foram obtidos na base do ESRI (Enviromental Systems Research Institute) e no banco de dados DIVA-GIS (< http://www.diva-gis.org/Data.htm>). O mapa base fitogeográfico de Pernambuco foi digitalizado a partir de Andrade-Lima (1960).

Os pontos georreferenciados foram marcados no mapa fitogeográfico de Pernambuco para análise da distribuição das espécies. O número de espécies por subzona fitogeográfica foi sumarizado com o auxílio do programa DIVA-GIS. Foram criadas gradículas de riqueza de espécies com células de $1^{\circ}$ por $1^{\circ}$, seguindo parcialmente o processo descrito por Hijmans \& Spooner (2001).

\section{Resultados e Discussão}

Chloris Sw., Prod. 1, 25. 1788.

Erva anual ou perene; colmo glabro, nós glabros. Bainha foliar glabra ou com tricomas marginais; lígula membranáceo-ciliada, com tricomas nas margens, circundadas por uma linha de tricomas híspidos, ou glabras; lâmina foliar glabra ou com tricomas esparsos em ambas as faces, plana, lanceolada, ápice agudo ou obtuso, margens lisas ou serreadas. Panícula vinácea, dourada, estramínea, acinzentada ou rósea, com 4-20 ramos, digitados ou subdigitados, unilaterais, espiciformes, eretos, pendentes, flexuosos ou em forma de "S", ramo antecedendo o conjunto às vezes presente ou ausente. Espiguetas basítonas com 2-6 antécios, todos ou apenas o primeiro e o segundo aristados; demais antécios neutros e desenvolvidos ou último antécio rudimentar. Glumas lanceoladas, ápice agudo, 1-3-nervadas, glabras; gluma inferior mútica, mucronada ou aristulada, gluma superior mútica ou aristulada. Antécio inferior hermafrodita, fértil, aristado; lema coriáceo, uni- ou 3-nervado, ápice agudo, piloso no dorso e na base, com tricomas marginais mais concentrados no ápice, ou piloso nas margens e na base; pálea membranácea, pouco menor que o lema.

\section{Chave de identificação das espécies de Chloris ocorrentes em Pernambuco}

1. Lâmina foliar com ápice obtuso.

2. Gluma inferior $1,8-2,5 \mathrm{~mm}$ compr., a superior $3-4,5 \mathrm{~mm}$ compr.; lâmina foliar 7-20 cm compr. 5. C. orthonoton

2'. Gluma inferior 3-6 mm compr., a superior 0,5-1 mm compr.; lâmina foliar 1,5-5 cm compr. .... 6. C. pycnothrix

1'. Lâmina foliar com ápice agudo.

3. Ambas as glumas aristuladas; ramos subdigitados ou alternos 3.C. exilis

3'. Glumas múticas ou apenas a gluma superior aristulada; ramos digitados. 
4. Lígula circundada por uma linha de tricomas híspidos de até ca. $5 \mathrm{~mm}$ compr.; panícula acinzentada 4. C. gayana

4'. Lígula glabra ou com tricomas esparsos na margem, atingindo até ca. de $3 \mathrm{~mm}$ compr.; panícula vinácea, dourada ou estramínea.

5. Gluma superior 3,5-4 mm compr.; ápice do lema inferior com um tufo de tricomas de até ca. 2 mm compr.

5'. Gluma superior 1,5-3 mm compr.; ápice do lema com concentração de tricomas marginais.

6. Antécios aristados; ramos eretos ou pendentes; panícula vinácea 1. C. barbata

6'. Apenas o terceiro e quarto antécios múticos; ramos flexuosos; panícula dourada 2. C. elata

1. Chloris barbata Sw., Fl. Ind. Occid. 1: 200. 1797.

Figs. 1a, 2a

Erva $10-75 \mathrm{~cm}$ alt., perene, formando touceiras esparsas. Bainha foliar glabra; lígula ca. $0,4 \mathrm{~mm}$ compr., com tricomas esparsos nas margens de até ca. $3 \mathrm{~mm}$ compr.; lâmina foliar 8-30 × $0,3-0,5 \mathrm{~cm}$, glabra em ambas as faces, ápice agudo, margens lisas. Panícula vinácea com 6-14 ramos, 2,5-7 cm compr., digitados, eretos ou pendentes, ramo antecedendo o conjunto ausente. Espiguetas com 3 antécios, todos aristados; segundo e terceiro antécios desenvolvidos. Glumas 1-3-nervadas, glabras; gluma inferior 1,2-2 mm compr., mútica, gluma superior 2-2,7 mm compr., mútica. Antécio inferior 2,5-5,5 $\mathrm{mm}$ compr., arista 3-5 $\mathrm{mm}$ compr.; lema 1,8-2,3 mm compr., 1-nervado, piloso no dorso e na base, com tricomas marginais mais concentrados no ápice, tricomas $0,5-1 \mathrm{~mm}$ compr. Material selecionado: Cabo, Suape, 8.III.1978, fr., $D$. Andrade-Lima et al. 9513 (IPA). Caruaru, 21.XII.1924, fl. e fr., B. Pickel 833 (IPA). Petrolina, Fazenda Experimental da UNIVASF, 4.II.2009, fl. e fr., J.R. Maciel et al. 955 (HVASF). Serra Talhada, 8.V.2002, fl. e fr., M.B. Costa-e-Silva et al. 70 (IPA).

Chloris barbata apresenta ampla distribuição nos trópicos do Velho e Novo Mundo (Molina \& Rúgolo-de-Agrasar 2004), mas no Brasil, Filgueiras (2012) a registrou apenas para a Bahia. Em Pernambuco esta espécie pode ser encontrada desde o Litoral até o Sertão. Floresce e frutifica ao longo de todo o ano na Zona da Mata e no período chuvoso na Zona da Caatinga, onde é mais rara. É uma forrageira de qualidade, mas de produção mediana.

É de fácil caracterização pela inflorescência plumosa de ramos eretos e coloração avermelhada. Dentre as espécies encontradas em Pernambuco, a que mais se aproxima dela é Chloris elata Desv. da qual se distingue pela coloração, flexibilidade e tamanho dos ramos.
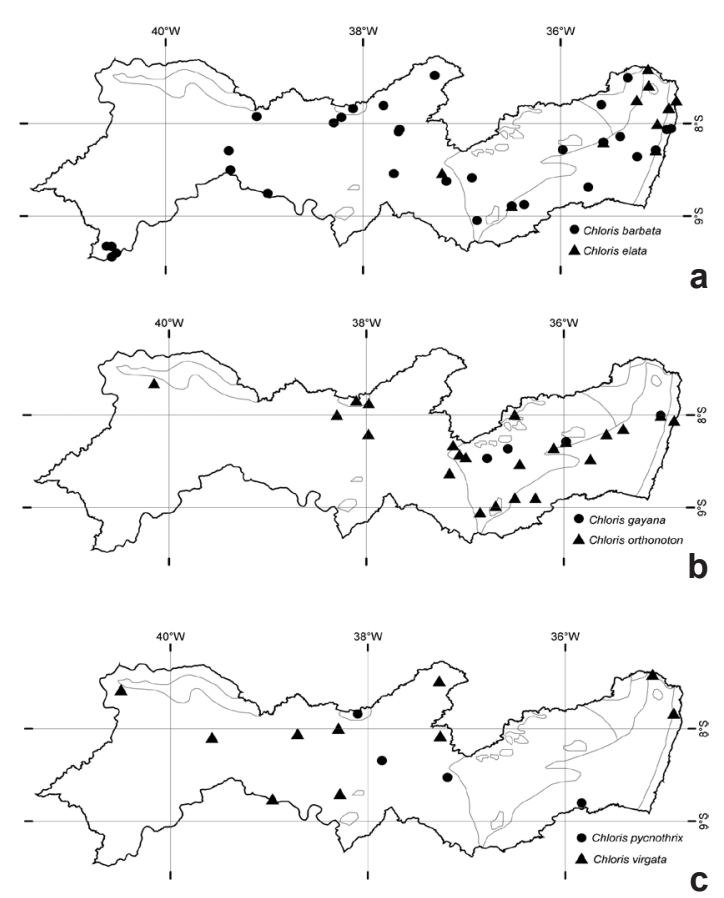

Figura 1 - a-c. Distribuição das espécies de Chloris no estado de Pernambuco - a. C. barbata, C. elata; b. C. gayana, C. orthonoton; c. C. pycnothrix, C. virgata. Figure 1 - a-c. Distribution of the species of Chloris in Pernambuco State - a. C. barbata, C. elata; b. C. gayana, C. orthonoton; c. C. pycnothrix, C. virgata.

2. Chloris elata Desv., Mém. Soc. Agric. Angers 1: 177.1831.

Figs. 1a, 2b

Erva $30-130 \mathrm{~cm}$ alt., perene, formando touceiras esparsas. Bainha foliar glabra; lígula ca. 0,5 $\mathrm{mm}$ compr., com tricomas esparsos nas margens de até ca. $3 \mathrm{~mm}$ compr.; lâmina foliar 5-30 × 0,3-1,2 cm, glabra em ambas as faces, ápice agudo, margens serreadas. Panícula dourada com 5-17 ramos, 5-15 cm compr., digitados, flexuosos, ramo antecedendo o 


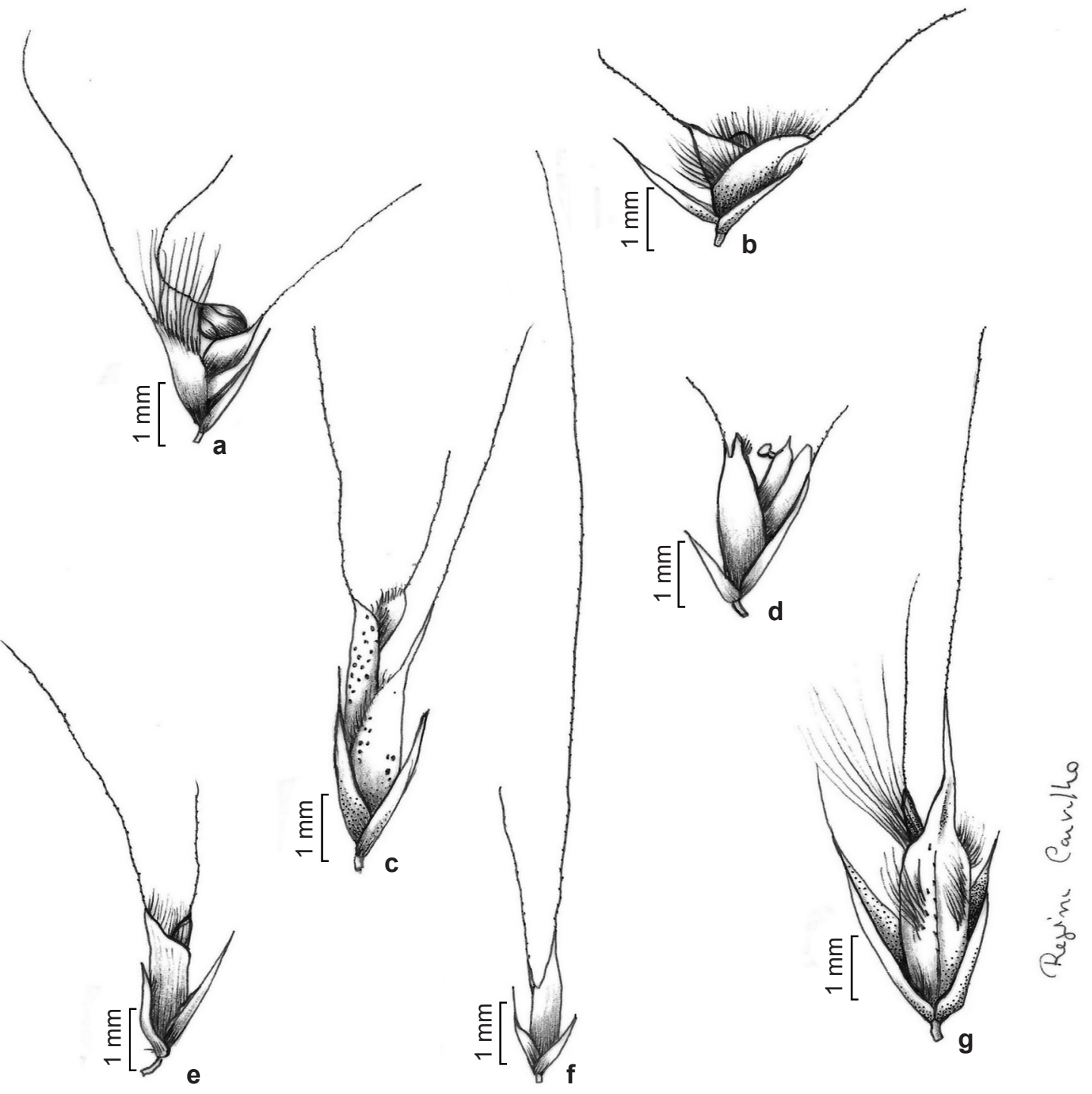

Figura 2 - a-g. espiguetas das espécies de Chloris ocorrentes em Pernambuco. a. C. barbata (D. Andrade-Lima \& J. Medeiros-Costa 192); b. C. elata (B. Pickel 768); c. C. exilis (D. Andrade-Lima 9319); d. C. gayana (E. Tenório 1089); e. C. orthonoton (B. Pickel 692); f. C. pycnothrix (E. Tenório 1042); g. C. virgata (A. Sarmento 377a).

Figure 2 - a-g. spikelets of the Chloris species ocurring in Pernambuco. a. C. barbata (D. Andrade-Lima \& J. Medeiros-Costa 192); b. C. elata (B. Pickel 768); c. C. exilis (D. Andrade-Lima 9319); d. C. gayana (E. Tenório 1089); e. C. orthonoton (B. Pickel 692); f. C. pycnothrix (E. Tenório 1042); g. C. virgata (A. Sarmento 377a).

conjunto ausente. Espiguetas com 3-4 antécios, o primeiro e o segundo antécio aristados; segundo e terceiro antécios desenvolvidos; quarto antécio rudimentar. Glumas lanceoladas, ápice agudo, 1-nervadas, com tricomas curtos sobre as nervuras; gluma inferior 1,2-2,2 $\mathrm{mm}$ compr., mútica, gluma superior $1,5-3 \mathrm{~mm}$ compr., mútica. Antécio inferior 2-4 mm compr., arista $2-5 \mathrm{~mm}$ compr.; lema $1-2,5 \mathrm{~mm}$ compr., 3-nervado, piloso no dorso e na base, com tricomas marginais mais concentrados no ápice, tricomas com até ca. $3 \mathrm{~mm}$ compr.

Material selecionado: Garanhuns, 18.X.1979, fl., D. Andrade-Lima et al. 9560 (IPA). Goiana, Estação experimental de Itapirema, 3.X.2006, fl. e fr., J.R. Maciel 357 (UFP). Gravatá, km 78 da BR-25, 26.VII.1966, fl. e fr., E.C. Tenório 133 (IPA). Nazaré da Mata, Mata de Alcaparra, 15.III.2002, fr., M.B. Costa-e-Silva et al. 2847 (IPA). 
Chloris elata ocorre desde os Estados Unidos até a Argentina e no Brasil possui distribuição ampla nas Regiões Nordeste, Centro-Oeste, Sudeste e Sul (Molina \& Rúgolo-de-Agrasar 2004; Filgueiras 2012). Em Pernambuco pode ser encontrada principalmente na Zona da Mata, sendo rara na Caatinga. Floresce e frutifica entre os meses de julho e dezembro. O potencial forrageiro dessa espécie é desconhecido.

Como já mencionado anteriormente, a espécie que mais se assemelha a $C$. elata é $C$. barbata, sendo que as duas se diferenciam com facilidade pela coloração da inflorescência, vinácea em C. barbata e dourada em C. elata, e pela flexibilidade dos ramos, eretos a pendentes em C. barbata e flexuosos em C. elata. Além disso, contribui para a separação das espécies o fato de que $C$. elata possui espiguetas com antécios mais laxos que C. barbata.

3. Chloris exilis Renv., Kew Bulletin 37(2): 323, f. 2.1982.

Fig. 2c

Erva 8-65 cm alt., anual, formando touceiras esparsas. Bainha foliar glabra; lígula ca. 0,2 mm compr., com tricomas nas margens de até ca. 4 mm compr.; lâmina foliar 2,5-15 × 0,15-0,5 cm, glabra em ambas as faces, ápice agudo, margens lisas. Panícula estramínea com 4-8 ramos, 3-9 cm compr., subdigitados, eretos, ramo antecedendo o conjunto às vezes presente. Espiguetas com 4-6 antécios, todos aristados; segundo, terceiro, quarto e quinto antécios desenvolvidos; sexto antécio rudimentar. Glumas 1-nervadas, glabras; gluma inferior $2-3,3 \mathrm{~mm}$ compr., aristulada, arístula $0,2 \mathrm{~mm}$ compr.; gluma superior 3,5-4,2 $\mathrm{mm}$, aristulada, arístula ca. $0,5 \mathrm{~mm}$ compr. Antécio inferior 5-7,5 mm compr., arista 4-7 mm compr.; lema 2-3,5 mm compr., 3-nervado, piloso nas margens e na base, glabro no dorso, ápice glabro.

Material examinado: Recife-Petrolina, 15.III.1989, fr., D. Andrade-Lima et al. 9319 (IPA).

Chloris exilis é endêmica do Brasil e ocorre na Caatinga da Bahia e Minas Gerais, segundo registros de literatura (Renvoize 1984; Filgueiras 2012), mas a imprecisão dos dados coletados não permitiu mapear a distribuição da espécie em Pernambuco. Aparentemente floresce e frutifica entre novembro e maio. Seu potencial forrageiro é desconhecido.

Dentre as espécies aqui tratadas se destaca por possuir ramos paucifloros, concentrados no ápice da inflorescência, subtendidos por um ramo basal, espiguetas achatadas dorsiventralmente, antécios com coloração acinzentada e pela presença de glândulas no lema, além dos colmos delgados e as lâminas foliares lanceoladas e curtas. Renvoize (1984) ressalta que C. exilis é muito parecida com Enteropogon mollis (Nees) Clayton, porém E. mollis é caracterizado por possuir espiguetas com 2 antécios e lema inferior fortemente comprimido dorsalmente.

4. Chloris gayana Kunth, Révis. Gramin. 1: 293, pl. 58. 1830 .

Figs. 1b, 2d

Erva $30-135 \mathrm{~cm}$ alt., perene, formando touceiras densas. Bainha foliar glabra; lígula ca. 0,2 mm compr., circundada por uma linha de tricomas híspidos de até ca. $5 \mathrm{~mm}$ compr.; lâmina foliar de $15-30 \times 0,2-0,4 \mathrm{~cm}$, glabra em ambas as faces, ápice agudo, margens serreadas. Panícula acinzentada com 9-20 ramos, 4-10 cm compr., digitados, eretos, dispostos aos pares, ramo antecedendo o conjunto ausente. Espiguetas com (2)3-4 antécios, o primeiro e o segundo antécio aristados; segundo e terceiro antécio desenvolvidos; quarto antécio rudimentar. Glumas 1-nervadas, glabras; gluma inferior 1,2-2 mm, mútica, gluma superior 2,5-3,5 mm compr., aristulada, arístula ca. $0,5 \mathrm{~mm}$ compr. Antécio inferior $0,5-2,5 \mathrm{~mm}$ compr., arista 1,8-5 mm compr.; lema 2,3-3,2 mm compr., 3-nervado, piloso nas margens e na base, raramente no dorso, tricomas de até ca. $1 \mathrm{~mm}$ compr.

Material selecionado: Alagoinhas, Fazenda Cajueiro Velho, 28.VIII.1995, fl. e fr., M. Alves et al. 19795 (UFP). São Lourenço da Mata, Tapera, VII.1928, fr., $B$. Pickel 1680 (IPA).

Chloris gayana é nativa da África e foi introduzida no Brasil se tornando naturalizada e tendo registros para os estados de São Paulo e Rio Grande do Sul (Smith et al. 1982; Molina \& Rúgolo-de-Agrasar 2004; Filgueiras 2012). Em Pernambuco, está distribuída desde o litoral até o agreste. Floresce e frutifica de julho a janeiro. Entre todas as espécies registradas, é a que apresenta o maior potencial forrageiro.

Distingue-se das demais espécies registradas neste estudo por formar densas touceiras. Os ramos da inflorescência nesta espécie geralmente são maiores (4-10 cm compr.) e mais numerosos (920 ramos) que os das demais espécies estudadas. Além disso, contribui para sua fácil caracterização o fato de os lemas serem curtamente aristados (aristas $1,8-5 \mathrm{~mm}$ compr.) e devido a isso não proporcionarem uma textura plumosa às suas inflorescências. 
5. Chloris orthonoton Döll, Fl. bras. 2(3): 64. 1878.

Figs. 1b, 2e

Erva $15-80 \mathrm{~cm}$ alt., perene, formando touceiras esparsas. Bainha foliar com tricomas marginais; lígula ca. $0,2 \mathrm{~mm}$ compr., com tricomas marginais de até ca. $7 \mathrm{~mm}$ compr.; lâmina foliar 7-20 × 0,4-0,6 $\mathrm{cm}$, com tricomas esparsos em ambas as faces ou não, ápice obtuso, margens serreadas. Panícula rósea com 4-12 ramos, 2-10 cm compr., digitados, eretos ou em forma de "S", ramo antecedendo o conjunto às vezes presente. Espiguetas com 2-3 antécios; o primeiro e o segundo antécio aristados; segundo antécio desenvolvido; terceiro antécio rudimentar ou desenvolvido. Glumas 1-nervadas, glabras; gluma inferior 1,8-2,5 mm compr., mucronada, gluma superior 3-4,5 mm compr., aristulada, arístula ca. $1,5 \mathrm{~mm}$ compr. Antécio inferior $0,8-1,7 \mathrm{~mm}$ compr., arista 8-15 mm compr.; lema 3-4 mm compr., 3-nervado, piloso no dorso, nas margens e na base e com tufo de tricomas no ápice, tricomas de até ca. $2 \mathrm{~mm}$ compr.

Material selecionado: Bonito, Pedra do Rodeador, 7.XI.2003, fl. e fr., J.R. Maciel \& W.C. Campelo 120 (IPA). Buíque, Vale do Catimbau, 18.VI.2008, fl. e fr., M.B. Costa-e-Silva 3663 (IPA). Fernando de Noronha, s.l., 18.X.1955, fl. e fr., D. Andrade-Lima 2166 (IPA). Goiana, Estação experimental de Itapirema, 3.X.2006, fl. e fr., J.R. Maciel 356 (RB). São Lourenço da Mata, Tapera, 18.I.1930, fl. e fr., B. Pickel 2299 (IPA).

Chloris orthonoton é endêmica do Brasil, onde está registrada para todas as Regiões com exceção do Norte do país (Filgueiras 2012). É encontrada desde o extremo leste até o oeste de Pernambuco. Floresce e frutifica entre agosto e janeiro, mas na Caatinga é encontrada produzindo flores e frutos nos meses de chuva. Seu potencial forrageiro é desconhecido.

Pode ser confundida com Chloris pycnothrix Trin. pois as duas possuem lâmina foliar com ápice obtuso e longas aristas vináceas, mas se separam facilmente tanto pelos aspectos indicados na chave, quanto pelos seguintes caracteres: $C$. orthonoton possui espiguetas com antécios mais imbricados, lâmina foliar lanceolada e nós não ramificados, ao contrário de C. pycnothrix.

6. Chloris pycnothrix Trin., Gram. Unifl. Sesquifl. 234. 1824.

Figs. 1c, 2f

Erva $10-35 \mathrm{~cm}$ alt., anual, formando touceiras esparsas. Bainha foliar com tricomas marginais; lígula ca. $1 \mathrm{~mm}$ compr., glabra; lâmina foliar 1,5-5 $\times 0,2-0,4 \mathrm{~cm}$, glabra em ambas as faces, ápice obtuso, margens serreadas. Panícula estramínea a rósea com 5-10 ramos, 4-10 cm compr., digitados, flexuosos, ramo antecedendo o conjunto ausente. Espiguetas com 2 antécios, ambos aristados; segundo antécio rudimentar. Glumas 1-nervadas, glabras; gluma inferior 0,3-0,6 mm compr., mútica, gluma superior $0,5-1 \mathrm{~mm}$ compr., aristulada, arístula ca. $0,2 \mathrm{~mm}$ compr. Antécio inferior 1-1,7 mm compr., arista 10-25 mm compr.; lema 1,5-2,2 $\mathrm{mm}$ compr., 3-nervado, piloso na base, tricomas $0,2-0,4 \mathrm{~mm}$ compr.

Material selecionado: Triunfo, 12.IX.1969, fl. e fr., E.C. Tenório 1043 (IPA).

Chloris pycnothrix ocorre amplamente nos trópicos do Novo e Velho Mundo (Molina \& Rúgolo-de-Agrasar 2004) e no Brasil, em todas as Regiões com exceção do Norte do país (Filgueiras 2012). Em Pernambuco é encontrada desde a Zona da Mata até a Caatinga. Floresce e frutifica de julho a janeiro. Apresenta potencial forrageiro mediano, pois tem boa qualidade, mas produção foliar média.

Caracteriza-se por apresentar a maior arista do lema dentre todas as espécies analisadas, a qual pode atingir até $20 \mathrm{~mm}$ de comprimento. Suas espiguetas são formadas por dois antécios, sendo apenas o inferior totalmente desenvolvido. No campo assemelha-se muito a $C$. virgata, mas uma análise mais cuidadosa das inflorescências revela as diferenças citadas anteriormente.

7. Chloris virgata Sw., Fl. Ind. Occid. 1: 203. 1797. Figs. 1c, $2 \mathrm{~g}$

Erva $10-75 \mathrm{~cm}$ alt., anual, formando touceiras esparsas. Bainha foliar glabra; lígula ca. $0,5 \mathrm{~mm}$ de compr., glabra; lâmina foliar 2-20 $\times 0,2-1,2 \mathrm{~cm}$, glabra em ambas as faces, ápice agudo, margens serreadas. Panícula estramínea com 4-19 ramos, 1,5-10 cm compr., digitados, eretos, ramo antecedendo o conjunto às vezes presente. Espiguetas com 2-3 antécios, o primeiro e o segundo aristados; segundo antécio desenvolvido; terceiro antécio desenvolvido ou rudimentar. Glumas 1-nervadas; gluma inferior 1,5-2,2 mm compr., mútica, gluma superior 3,5-4 $\mathrm{mm}$ compr., aristulada, ca. $1 \mathrm{~mm}$ compr. Antécio inferior 5-10 mm compr., arista 5-15 $\mathrm{mm}$ compr.; lema 1,5-2,2 mm compr., 3-nervado, piloso no dorso, nas margens e na base, tufo de tricomas presente no ápice, tricomas de até ca. $2 \mathrm{~mm}$ compr.

Material selecionado: Araripina, Chapada do Araripe, 24.III.1970, fr., L. Ferraz (IPA 18475). Belém do São Francisco, 21.VII.1967, fl. e fr., E.C. Tenório 356 (IPA). Itambé, Estação Experimental do IPA, 5.X.2006, fl. e fr., J.R. Maciel 364 (UFP). Mirandiba, Serra do Tigre, 17.IV.2007, fl. e fr., J.R. Maciel et al. 412 (UFP). 
Chloris virgata ocorre amplamente nos trópicos do Novo e Velho Mundo (Molina \& Rúgolo-deAgrasar 2004). No Brasil está registrada para os estados do Ceará, Sergipe e Bahia (Filgueiras 2012). Em Pernambuco, encontra-se distribuída desde o extremo leste ao oeste. Floresce e frutifica ao longo de todo ano. Seu potencial forrageiro é desconhecido.

Assemelha-se a C. orthonoton e a C. barbata pelo aspecto da inflorescência com ramos floríferos concentrados no ápice do colmo e pela textura plumosa da inflorescência. No entanto, a espigueta de C. virgata é nitidamente mais laxa que as das outras duas espécies, que possuem antécios fortemente imbricados mesmo após a maturação do fruto.

\section{Riqueza e distribuição}

Neste trabalho foram confirmadas sete espécies em Pernambuco, sendo elas: Chloris barbata, C. elata, C. exilis, C. gayana, C. orthonoton, $C$. pycnothrix e $C$. virgata. As espécies C. exilis e C. gayana não foram registradas para Pernambuco por Molina \& Rúgolo-de-Agrasar (2004). Por sua vez, Filgueiras (2012) citou apenas $C$. elata, $C$. orthonoton e $C$. pycnothrix para Pernambuco. Dessa forma o presente estudo amplia na Lista da Flora do Brasil as ocorrências de C. barbata, C. exilis, C. gayana e C. virgata.

Em geral o gênero Chloris mostra uma ampla distribuição no contexto fitogeográfico pernambucano, como pode ser observado na Figura 1. Chloris barbata, C. orthonoton e $C$. virgata podem ser encontradas ocorrendo desde o extremo leste até o extremo oeste de Pernambuco. Por outro lado, C. elata, C. gayana e C. pycnothrix apresentam uma restrição maior na faixa de amplitude das suas populações.

Neste estudo, as subzonas fitogeográficas de Pernambuco apresentaram um padrão de riqueza de espécies similar (Fig. 3a). A riqueza das subzonas fitogeográficas variou entre três e cinco espécies, sendo que na subzona da mata úmida, e na subzona do sertão foram registradas cinco espécies, quatro na zona do litoral e três nas subzonas da mata seca, da mata serrana e do agreste.

Essa distribuição de riqueza homogênea das espécies de Chloris não encontra correspondente nos casos registrados na literatura. Maciel et al. (2010) e Maciel \& Costa-e-Silva (2011) registraram para as gramíneas Andropogon L. e Paspalum L. respectivamente, uma redução da riqueza de espécies no sentido leste-oeste. Segundo os autores, a longitude $36^{\circ}$ evidencia uma barreira geográfica para a colonização de muitas espécies que não apresentam adaptações à sazonalidade climática encontrada na caatinga, conforme foi descrito por Andrade-Lima (1960, 1981).

No entanto, este padrão de riqueza de espécies observado para Andropogon e Paspalum além de outros gêneros de famílias distintas, como Heliotropium L. (Boraginaceae) (Melo \& Sales 2004), Oxalis L. (Oxalidadaceae) (Abreu et al. 2008), Phyllanthus L. (Phyllanthaceae) (Silva \& Sales 2007) e Staelia Cham. \& Schltdl. (Rubiaceae) (Souza \& Sales 2004), não é aplicável para Chloris (Fig. 3b).

As espécies de Chloris registradas para Pernambuco, ocorrem exclusivamente em ambientes abertos, o que as caracteriza como heliófitas estritas. Os habitats podem ser bordas de fisionomias florestais da Floresta Atlântica, solos arenosos e pedregosos da Caatinga e restingas. Chloris barbata e C. orthonoton são duas espécies que apresentam comportamento ruderal, sendo mais frequentes em margens de estradas, canais, invadindo jardins e plantações. Chloris virgata também pode ser encontrada como ruderal na Caatinga, onde suas populações são mais abundantes.
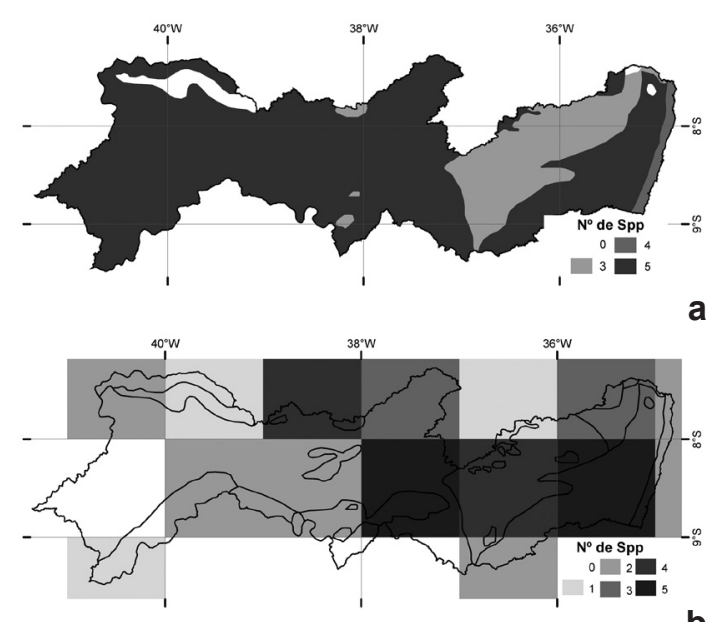

Figura 3 - Riqueza de espécies de Chloris em Pernambuco - a. distribuição da riqueza de Chloris com base nos registros de número de espécies por subzona fitogeográfica; b. grid de $1^{\circ}$ por $1^{\circ}$ mostrando a distribuição da riqueza de espécies de Chloris com base nos registros do número de espécies no estado. Figure 3 - Richness of the species of Chloris in Pernambuco State - a. distribution of richness of Chloris based on records of species number by phytogeographic subzone; b. $1^{\circ}$ by $1^{\circ}$ grid showing the richness distribution of Chloris species based on records of species number in the State. 


\section{Agradecimentos}

$\mathrm{O}$ primeiro e o segundo autor agradecem ao $\mathrm{CNPq}$ e à Facepe a concessão de bolsas de iniciação científica. E a terceira autora agradece ao CNPq e à Facepe a bolsa DCR concedida durante a realização desta pesquisa. Os autores são gratos a toda a equipe do IPA, em especial a Dra. Rita de Cássia Araújo Pereira a concessão do espaço do herbário; e aos revisores anônimos e editores da revista Rodriguésia a valiosa contribuição.

\section{Referências}

Abreu, M.C.; Carvalho, R. \& Sales, M.F. 2008. Oxalis L. (Oxalidaceae) no estado de Pernambuco, Brasil. Acta Botanica Brasilica 22: 399-416.

Anderson, D.E. 1974. Taxonomy of the genus Chloris (Gramineae). Brighan Young University Science Bulletin Biological series 19: 1-133.

Andrade-Lima, D. 1960. Estudos fitogeográficos de Pernambuco. Arquivos do IPA 5: 305-341.

Andrade-Lima, D. 1981. The Caatingas dominium. Revista Brasileira de Botânica 4: 149-153.

Clayton, W.D. \& Renvoize, S.A. 1986. Genera graminum: grasses of the world. Royal Botanic Gardens, Kew. 389p.

Filgueiras, T.S. 2012. Chloris. In: Forzza, R.C. et al. (eds.). Lista de espécies da flora do Brasil. Jardim Botânico do Rio de Janeiro. Disponível em < http:// floradobrasil.jbrj.gov.br/2011/FB013081>. Acesso em 22 Jun 2012.

GPWG. 2001. Phylogeny and subfamilial classification of the grasses (Poaceae). Annals of the Missouri Botanical Garden 88: 373-457.

Hijmans, R.J. \& Spooner, D.M. 2001. Geographic distribution of wild potato species. American Journal of Botany 88: 2101-2112.

Hijmans, R.J.; Cruz, M.; Rojas, E. \& Guarino, L. 2001. DIVA-GIS, version 1.4. A geographic information system for the management and analysis of genetic resources data. Manual. International Potato Center and International Plant Genetic Resources Institute, Lima. 73p.

Longhi-Wagner, H.M. 2001. Tribo Cynodonteae (Chlorideae). In: Longhi-Wagner, H.M.; Bittrich, V.; Wanderley, M.G.L. \& Shepherd, G.J. (eds.). Flora fanerogâmica do estado de São Paulo. Vol. 1. Hucitec, São Paulo. Pp. 49-61.
Maciel, J.R. \& Costa-e-Silva, M.B. 2011. Distribuição e taxonomia de Andropogon L. (Poaceae) em Pernambuco, Brasil. Pesquisas, Botânica 62: $117-$ 128.

Maciel, J.R.; Oliveira, R.C. \& Alves, M. 2010. Aspectos da distribuição e conservação de Paspalum L. (Poaceae) em Pernambuco. Hoehnea 37: 801-812.

Melo, J.I.M. \& Sales, M.F. 2004. Heliotropium L. (Boraginaceae-Heliotropioideae) de Pernambuco, Nordeste do Brasil. Rodriguésia 55: 65-87.

Molina, A.M. 1996. Revisión taxonómica del género Eustachys Desv. (Poaceae: Chloridoideae, Cynodonteae) de Sudamérica. Candollea 51:225-272.

Molina, A.M. \& Rúgolo-de-Agrasar, Z.E. 2004. Revisión taxonómica de las especies del género Chloris (Poaceae: Choridoideae) em Sudamérica. Candollea 59: 347-428.

Nascimento, M.P.S.C.B. \& Renvoize, S.A. 2001. Gramíneas forrageiras naturais e cultivadas na região meio-norte. Embrapa Meio-Norte, Teresina. 196p.

Pereira, S.C. \& Barreto, I.L. 1985. O gênero Chloris Swartz (Gramineae) no Rio Grande do Sul. Rodriguésia 37: 9-20.

Peterson, P.M.; Romaschenko, K. \& Johnson, G. 2010. A classification of the Chloridoideae (Poaceae) based on multi-gene phylogenetic trees. Molecular Phylogenetics and Evolution 55: 580-98.

Renvoize, S.A. 1984. The grasses of Bahia. Royal Botanic Gardens, Kew. 301p.

Silva, M.J. \& Sales, M.F. 2007. Phyllanthus L. (Phyllanthaceae) em Pernambuco, Brasil. Acta Botanica Brasilica 21: 79-98.

Smith, L.B.; Wasshausen, D.C. \& Klein, R.M. 1982. Gramíneas: Flora ilustrada catarinense. Vol. 1. Herbário Barbosa Rodrigues, Itajaí. 440p.

Soreng, R.J.; Davidse, G.; Peterson, P.M.; Zuloaga, F.O.; Judziewicz, E.J.; Filgueiras, T.S. \& Morrone, O. 2000. Catalogue of New World grasses. Disponível em < http://mobot.mobot.org/W3T/Search/nwgc. html>. Acesso em 20 Jun 2012.

Souza, E.B. \& Sales, M.F. 2004. O gênero Staelia Cham. \& Schltdl. (Rubiaceae-Spermacoceae) no estado de Pernambuco, Brasil. Acta Botanica Brasilica 18: 919-926.

Thiers, B. 2012 (continuamente atualizado). Index Herbariorum: a global directory of public herbaria and associated staff. Disponível em <http:// sweetgum.nybg.org/ih/>. Acesso em 22 Jun 2012. 


\section{Lista de exsicatas}

Albuquerque, N.A. 313 (2). Alves, M. UFP-19795 (4), UFP-8495 (1), Andrade-Lima, D. 191 (2), 192 (1), 212 (1), 2166 (5), $66-4465$ (2), 8041 (7), 9319 (3), 9409 (7), 9513 (1), 9514 (5), 9560 (2). Araújo, D. 965 (1). Araujo, F. 81 (7). Barral, E.C. 4 (1). Bocage, A. IPA-73372 (5). Burgos, N. IPA-55862 (5). Campêlo, C.R. 1525 (1), 1914 (1). Cardoso, A. IPA-45124 (5). Carvalho, M.M.P. 24 (1). Castro, R.A. 15 (1). Cavalcanti, M.F. 22 (1). Coelho, M. 29 (5). Coradin, L. 2458 (4). Costa-e-Silva, M.B. 2847 (2), 2906 (1), 3663 (5), 3678 (1), 3705 (6). Félix, L.P. 7968 (1). Ferraz, L. IPA-18475 (7). Ferraz, N.M.S. 42 (1), 54 (1). Ferreira, C. IPA-83818 (5), IPA-83863 (5), IPA-83880 (1), 83975 (1), 84001 (7), Ferreira, J.V.A. 28 (1), Florêncio, M.A.P. UFP-3853 (1). Fotius, G. 3267 (1). Galindo, R.P. 43 (5), 44 (1), IPA-54334 (1). Gallindo, F. 01 (5), 03 (5), IPA-60126 (1). Giulietti, A.M. 2169 (1), 5359 (1). Gomes, M.L. 172 (1). Gomes, P. 279 (7). Heringer, E.P. 563 (5). Kimmel, T. 66 (2). Leite, M.S. 677 (1). Lima, V.C. 15 (5), 70 (1). Maciel, J.R. 120 (5), 123 (5), 356 (5), 357 (2), 364 (7), 412 (7), 955 (1), 1340 (6). Maia, L.M.C. IPA-58711 (1). Melo, L. 9H (7). Miranda, A.M. 3283 (1). Nascimento, J.P.B. 10 (1). Oliveira, M.A. 3890 (7). Pereira, R. 2868 (1). Pickel, B. 1031 (5), 1394 (2), 1680 (4), 1920 (1), 1997 (1), 1998 (2), 2299 (5), 3197 (5), 692 (5), 768 (2), 833 (1). S/C IPA-1152 (1). Sarmento, A. 377 (2), 377A (7). Silva, H.L.C. 36 (1). Silva, V.M. IPA-44506 (7). Siqueira-Filho, J.A. 682 (6), 2448 (1). Sousa, L.G. 149 (1), 198 (1). Souza, E. 16 (1). Tavares, S. UFP-734 (1). Tenório, E.C. 99 (5), 133 (2), 134 (5), 144 (1), 182 (2), 191 (5), 342 (1), 356 (7), 373 (2), 646 (2), 664 (2), 738 (5), 773 (5), 832 (5), 846 (5), 858 (5), 869 (5), 926 (5), 937 (5), 941 (5), 944 (1), 954 (5), 977 (5), 981 (5), 997 (5), 1001 (6), 1027 (1), 1035 (5), $1042(5), 1043(6), 1089(4), 1102(5), 1105(5)$. 